\title{
ELECTROPHYSIOLOGY IN SOME ANIMAL AND HUMAN HEREDITARY DISEASES INVOLVING THE RETINAL PIGMENT EPITHELIUM
}

\author{
SVEN ERIK G. NILSSON and ANDERS WRIGSTAD \\ Linköping, Sweden
}

\begin{abstract}
SUMMARY
The present paper surveys slow electrophysiological responses recorded by a d.c. technique in some hereditary eye diseases involving the retinal pigment epithelium (RPE) in animals (English setter dogs and Polish Owczarec Nizinny (PON) dogs with ceroid lipofuscinosis and Briard dogs with a slowly progressive rod-cone dystrophy associated with RPE inclusions) and in humans (Best's disease). The electroretinogram c-wave was typically either decreased in amplitude, lacking or replaced by a negative wave. These c-wave changes could be seen at fairly early stages of disease, when the a- and b-waves of the electroretinogram were still within normal limits.
\end{abstract}

The a- and b-waves, which are fast potentials of the regular a.c. electroretinogram (ERG), tell us the functional status of the photoreceptors and the inner retina. In diseases in humans and in animals affecting the retinal pigment epithelium (RPE) primarily or in conjunction with a retinal disease, it is of interest, however, to study additional potentials which are more directly associated with RPE function, and which may reveal early RPE damage. These potentials are much slower potentials, such as the ERG c-wave and the light peak, requiring the more elaborate d.c. recording technique. The light peak can be recorded also in the electro-oculogram (EOG).

The c-wave of the ERG is the sum of a positive component (PI) from the RPE and a negative component (slow PIII) from the Müller cells. In cats and in rabbits, PI is much larger than slow PIII, resulting in a large positive c-wave. In dogs and in humans, the two potentials are more similar in amplitude, reflected in a smaller c-wave or, in rare

\footnotetext{
Presented at a symposium in London, 29 September 1995, in honour of Professor Geoffrey Arden.

Correspondence to: S. E. G. Nilsson, Department of Ophthalmology, University of Linköping S-581 85 Linköping, Sweden.
}

cases, no c-wave at all. PI represents the difference in hyperpolarisation between the apical and basal membranes of the RPE in response to the decrease in extracellular potassium concentration occurring in the subretinal space during light stimulation. Simultaneously, the potassium change also hyperpolarises the apical membrane of the Müller cells, generating slow PIII. ${ }^{1-8}$

In RPE disease or damage, the PI response will be impaired. This was shown experimentally by means of intravenously injected sodium iodate, a drug toxic to the $\operatorname{RPE}^{9-12}$ (Fig. 1). The a- and b-waves will survive for some time, while the positive c-wave is replaced by a negative potential (slow PIII) almost immediately. The opposite situation is seen in Müller

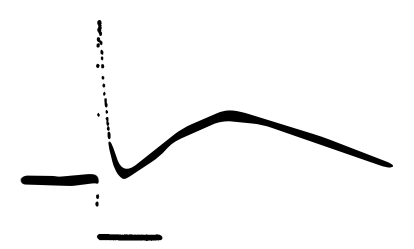

Ta
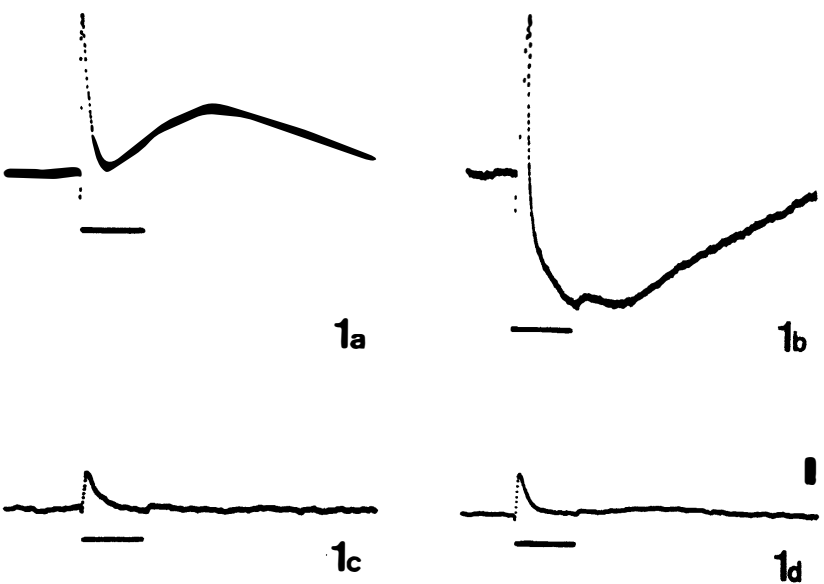

Fig. 1. The d.c. recorded sheep electroretinogram (ERG). (a) Normal control with $a$-, b- and c-waves. (b) Early stage (12 minutes) after sodium iodate injection. The $c$-wave is abolished and replaced by a cornea-negative potential. (c) and $(d)$ Later stage (3 days) after sodium iodate injection. There are markedly reduced $a$-and $b$-waves. The c-wave is abolished or can barely be seen. The cornea-negative potential has disappeared. Stimulus duration: 1.0 second. Stimulus intensity: about 5 log units above the b-wave threshold. Amplitude and time calibrations: $100 \mu \mathrm{V}$ and 1.0 second, respectively. (From Nilsson et al. ${ }^{12}$ with permission.) 
cell damage, when there is impairment of slow PIII. This was demonstrated experimentally by intravitreal injection of DL- $\alpha$-aminoadipic acid, toxic to the Müller cells ${ }^{13}$ (Fig. 2). The b-wave disappeared and the c-wave increased markedly. On the basis of these and other experiments, it may be concluded that an increase in c-wave amplitude may be caused by either an enhancement of PI or an impairment of slow PIII, while a decrease in c-wave amplitude may reflect either an impairment of PI or an enhancement of slow PIII.

The standing potential of the eye (SP) arises largely in the RPE, the apical membrane of which is more hyperpolarised than the basal one. This voltage across the eye (about $10 \mathrm{mV}$ ) is modified by many other events in the RPE and in the retina, such as the ERG potentials and the light peak. The positive light peak represents a very slow potential shift in the RPE with a maximum amplitude (often $3-5 \mathrm{mV}$ ) at 10-12 minutes after the start of light stimulation in human. ${ }^{14}$ The corresponding figures for the dog are approximately $2-3 \mathrm{mV}$ and $6-8$ minutes. ${ }^{15}$ The light peak is generated as a depolarisation of the basal RPE membrane. ${ }^{16}$ The mechanism behind this sepolarisation is suggested to be an adrenaline activation of apical $\alpha_{1}$-adrenergic receptors, increasing the intracellular RPE concentration of calcium ions as a second messenger, which in turn increases basal membrane chloride conductance. ${ }^{17-20}$

The light peak may be recorded as the $\mathrm{EOG}^{21}$ or directly from the cornea, using d.c. equipment. ${ }^{22,23} \mathrm{~A}$ light peak abnormality is likely to reflect RPE impairment. However, since the light peak is dependent upon a messenger (e.g. adrenaline) from the retina, a decrease in the release of such a messenger may also be involved. It was shown that experimental occlusion of the retinal circulation in the monkey abolished the light peak. ${ }^{24}$

The present paper reviews c-wave and light peak abnormalities in animal and human hereditary diseases involving the RPE, studied earlier as well as very recently in our laboratory.
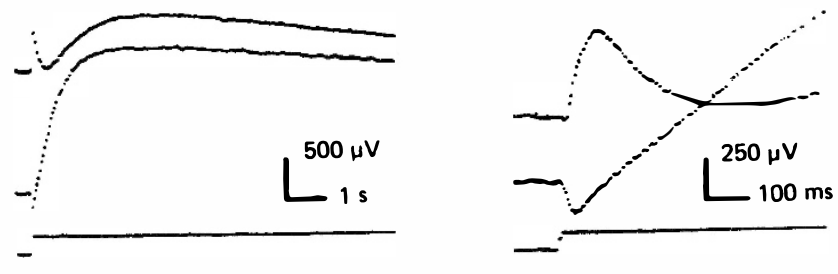

A

Fig. 2. The d.c. recorded rabbit ERG $13.5 \mathrm{~h}$ after injection of $D L$ - $\alpha$-aminoadipic acid $(\alpha$-AAA) into one eye (lower traces) and saline into the contralateral eye (upper traces). (A) A dramatic increase in c-wave amplitude is seen in the $\alpha-A A A$ eye. (B) On an expanded time scale, the disappearance of the $b$-wave and the increase in a-wave amplitude in the $\alpha-A A A$ eye are clearly seen. Stimulus intensity: 1200 $\mathrm{cd} / \mathrm{m}$. (After Welinder et al. ${ }^{13}$ with permission.)

\section{MATERIAL AND METHODS}

Six English setters with ceroid lipofuscinosis, a disease leading to visual problems and neurological symptoms, such as ataxia, aged 11-25 months, and three healthy controls, aged 6, 24 and 34 months, were investigated electrophysiologically for slow potentials. ${ }^{15}$ Several other dogs were studied ultrastructurally. ${ }^{25,26}$

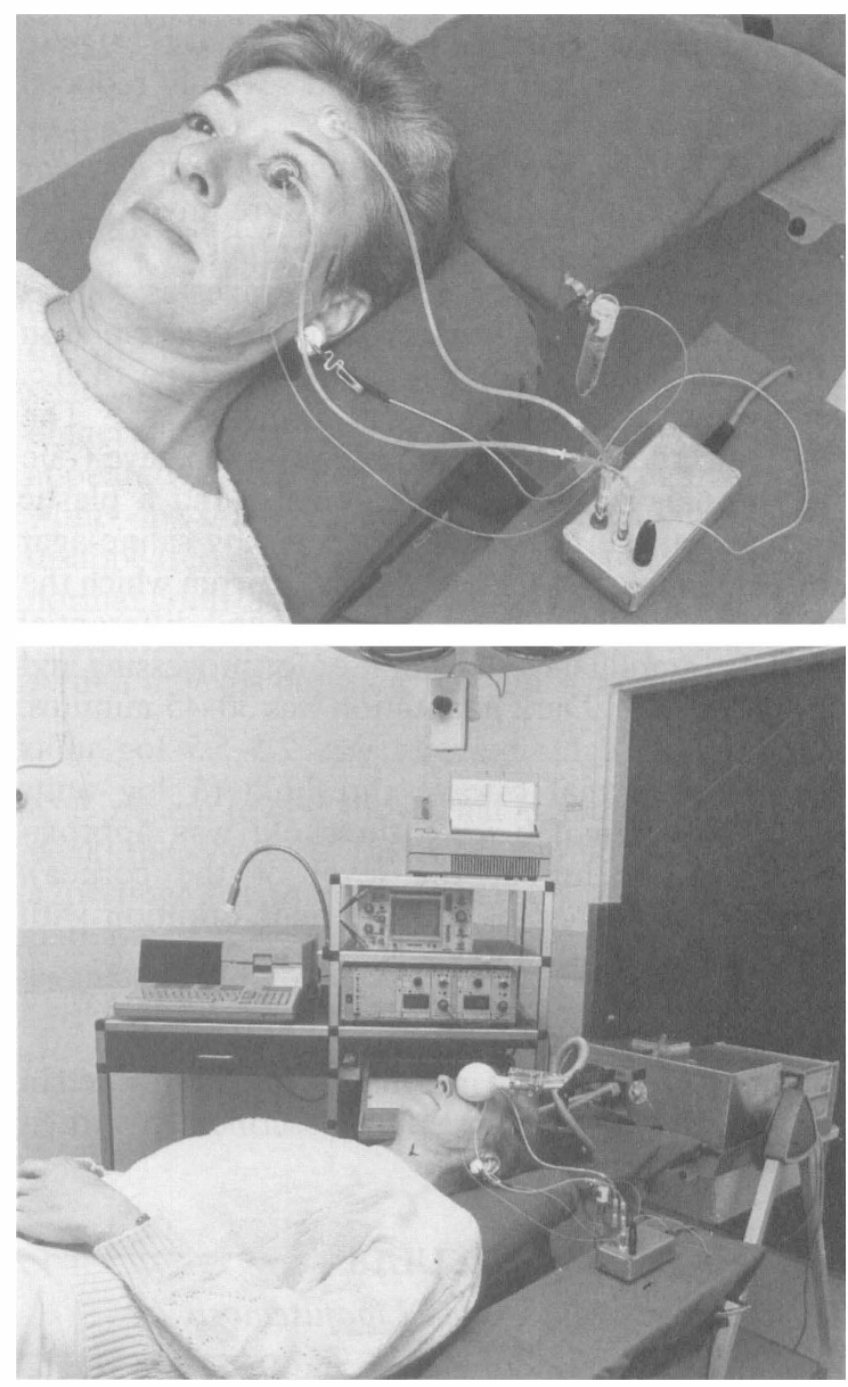

Fig. 3. The d.c. recording equipment used in clinical or in animal experimental work. Above: A contact lens on the eye and a plastic chamber on the forehead are connected by means of saline-agar bridges to matched calomel half-cells (recording and reference electrodes), plugged into a preamplifier. To provide well-defined suction, the contact lens is equipped with a second tube, ending in a test-tube with saline, $20 \mathrm{~cm}$ below the eye. The earlobe is grounded. Below: The light stimulation unit, controlled by the computer, with fibre optics and a small single-eye ganzfeld, is seen to the right. An LED, also controlled by the computer, for fixation, is mounted under the lamp, about $1 \mathrm{~m}$ above the eye. The signal processing and display unit is seen in the centre of the figure with a computer and a display screen to the left, and a thermoprinter, an oscilloscope, d.c. amplifiers, and a plotter to the right. Not seen are the flexible disc memory and multiprogrammer. 
One Polish Owczarek Nizinny (PON) dog with neuronal ceroid lipofuscinosis, 2 years old, was studied electrophysiologically for slow potentials and ultrastructurally. ${ }^{27}$

Eleven Swedish Briard dogs with a slowly progressive rod-cone dystrophy associated with RPE inclusions, aged 5 weeks to 7 years, and 8 controls, aged 6 weeks to 13 years, were investigated morphologically. ${ }^{28,29}$ Five affected dogs, 7-12 months old, and 3 controls, 1-4 years old, were studied electrophysiologically for slow potentials. ${ }^{30}$ These dogs were all night blind and had severely reduced day vision.

Six patients with Best's disease/vitelliform macular degeneration, aged 10-48 years, were investigated electrophysiologically for slow potentials. ${ }^{31}$

$E R G$ recordings for a-, b- and c-waves as well as $S P$ and light peak recordings were all performed in animals and in humans with the same type of d.c. equipment, described in detail elsewhere. ${ }^{22,23}$ The set-up included a scleral contact lens on the eye (one eye in humans, two eyes in animals) and a plastic chamber on the forehead, connected by saline-agar bridges to matched calomel half-cells, from which the signals passed through preamplifiers and differential input d.c. amplifiers to a computer for processing and storage (Fig. 3). Dark adaptation was 30-45 minutes. The stimulus light intensity was 2.5-5.5 log units above the normal b-wave threshold (5 log units above the normal b-wave threshold was approximately 75000 lux at the level of the cornea), delivered as flashes of 1-20 seconds duration with an interval of $30-180$ seconds.

In some cases, $30 \mathrm{~Hz}$ cone flicker responses were recorded with photopic stimulus flashes.

The EOG recordings in humans were performed in accordance with the procedure described by Arden and Kelsey. ${ }^{21}$

\section{RESULTS}

\section{English Setters with Ceroid Lipofuscinosis}

In canine ceroid lipofuscinosis, the RPE and retinal ganglion cells become markedly damaged through accumulation of large amounts of fingerprint or myelin-like inclusions, while the other retinal cells, including the photoreceptors, were much better preserved until late stages. The Müller cells showed fewer inclusions than any of the other retinal cells. Fig. 4 shows parts of two RPE cells, one of which is markedly damaged, from a 25-month-old affected dog.

The d.c. ERG recordings from normal and affected English setters are demonstrated in Figs. 5 and 6, respectively. At early stages of disease (Fig. 6A, B), the ERG was similar to that in control dogs. At moderate stages (Fig. 6C, D), the trough after the $\mathrm{b}$-wave was deep and the c-wave was replaced by a negative potential. The b-wave in some cases was reduced in amplitude. At advanced stages (Fig. 6E, F), the ERG was of a 'low-voltage' type with minimal or no a- and b-waves, followed by a more or less straight line at the site of the c-wave.

The light peak in a control dog is shown in Fig. 7A. It was reduced in amplitude at moderate stages of diseases (Fig. 7B), while at advanced stages it was minimal and markedly delayed (Fig. 7C).

\section{Polish Owczarek Nizinni (PON) Dogs}

A strain of PON dogs was found by our group to be affected by neuronal ceroid lipofuscinosis, causing blindness with time and neurological problems such as ataxia. The RPE of a 2-year-old dog showed abundant inclusions (Fig. 8), more numerous in the central part of the fundus than in the periphery. In some of the inclusions, fingerprint-like structures were seen, while others were more homogeneous. The photoreceptors were reduced in number in all areas, and the outer segments of remaining photoreceptors were often disorganised.

No scotopic a- and b-waves were found, but reduced $30 \mathrm{~Hz}$ cone flicker responses were obtained. At high stimulus intensities, a very deep negative response was seen at the site of the c-wave in d.c. ERG recordings (Fig. 9, lower trace). Under these conditions, the control dog also showed a slight negativity at the site of the c-wave (Fig. 9, upper trace), not totally uncommon in dogs.

\section{Briard Dogs with a Slowly Progressive Rod-Cone Dystrophy and RPE Inclusions}

This strain of Briard dogs showed RPE inclusions (Fig. 10), mainly centrally in the fundus. These inclusions were totally different from those in the other two breeds of dogs described. They were electron-lucent and showed occasional signs of a somewhat more electron-dense content. The photoreceptor outer segments were disoriented and disorganised, mainly in rods, and more in the periphery of the fundus than centrally. In the oldest dog, 7 years of age, loss of photoreceptors and of inner retinal neurons was found, mainly in the periphery.

Normal control dogs showed a-, b- and c-waves (Fig. 11). No certain scotopic a- and b-waves but reduced cone flicker ERG responses were seen in affected dogs. At higher stimulus intensities, the d.c. ERG showed a markedly delayed response, which was entirely negative (Fig. 12). This response had an extremely long latency of up to 7 seconds at moderately high intensities. At the highest intensity used (75 000 lux at the level of the cornea), it was still as long as 0.2 seconds. 


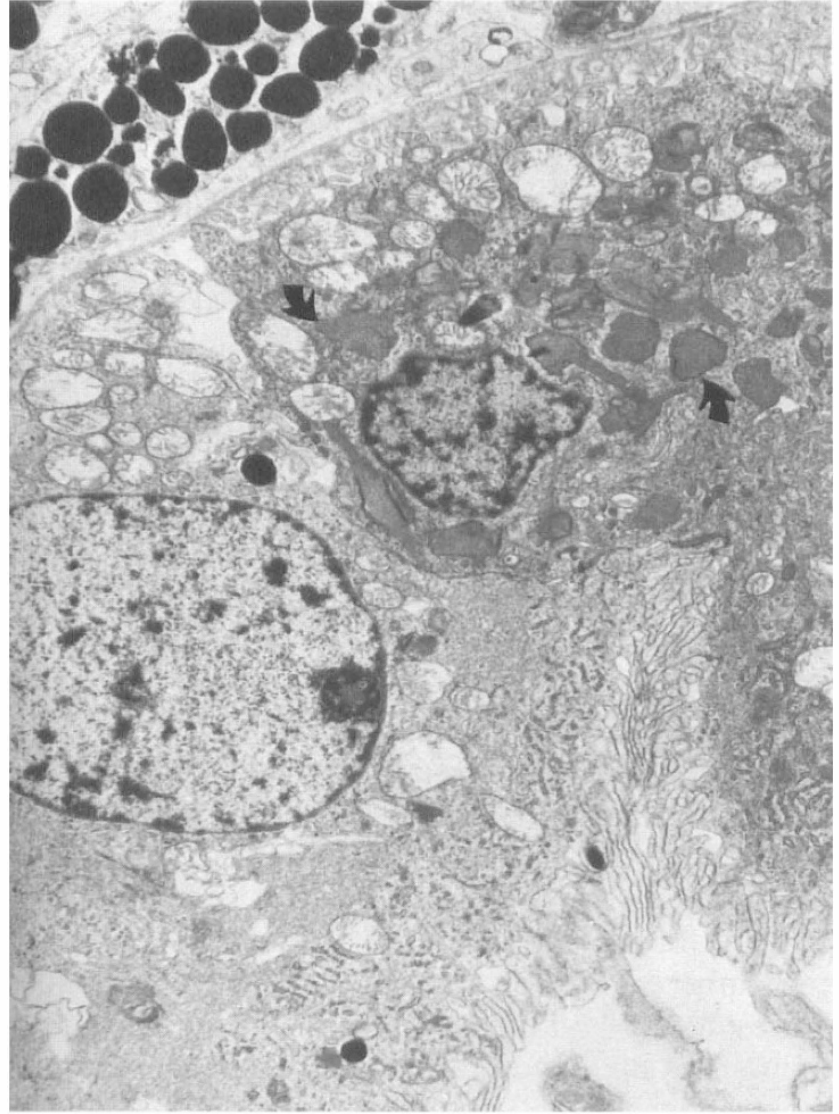

Fig. 4. Retinal pigment epithelium from an English setter with ceroid lipofuscinosis, 25 months old. The non-tapetal region shows a pyknotic cell with large amounts of free ceroid (arrows) and loss of melanin granules. The cell to the left also contains a greatly reduced number of these granules. $\times 9700$. (From Nilsson et al. ${ }^{15}$ with permission.)
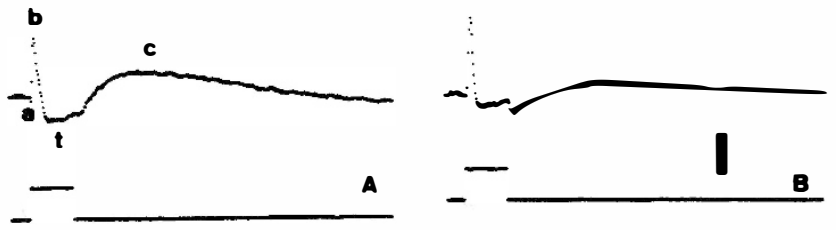

Fig. 5. ERGs with $a$-, $b$ - and $c$-waves and the trough $(t)$ after the b-wave from two healthy control English setters: (A) 6 months old; (B) 24 months old. Stimulus intensity: 4 log units above $b$-wave threshold. A stimulus duration of 1 second is indicated on the lower line. Amplitude calibration: $100 \mu \mathrm{V}$. (From Nilsson et al. ${ }^{15}$ with permission.)

\section{Best's Disease}

The d.c. ERGs were recorded in all 6 patients with Best's disease. The a- and b-waves were normal in all cases. At the lower stimulus intensities used, the bwave was followed by a more or less straight line at the site of the c-wave in 5 patients, whereas in the sixth patient a minimal c-wave was present. At higher stimulus intensities a negativity (Fig. 13) appeared at the site of the c-wave in 5 patients, while in the sixth patient the minimal c-wave disappeared. (For comparison, a d.c. ERG from a normal control is seen in Fig. 14, top trace.)

The EOG was pathological in all 6 patients, with Arden indexes between 108 and 125.

\section{DISCUSSION}

The present review shows that in addition to the light peak, the c-wave of the ERG can be used in animal experiments and in examinations of humans (e.g. patients with Best's disease) to study RPE changes, even at fairly early stages, when the a- and b-waves are within normal limits.
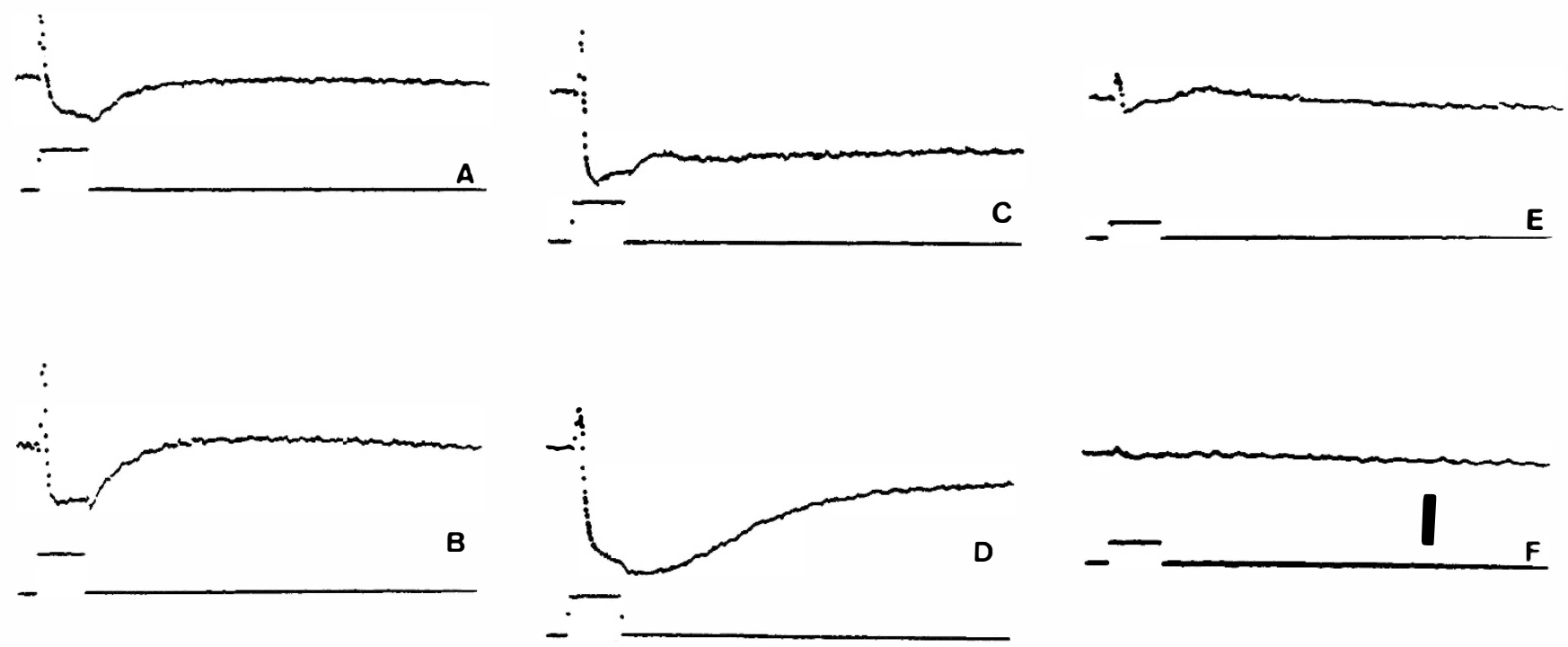

Fig. 6. ERGs from English setters with ceroid lipofuscinosis. (A), (B) No obvious ERG changes; 18.5 and 11 months old, respectively. (C), (D) Moderate ERG changes concerning particularly the c-wave and the trough after the $b$-wave; 20 and 24 months old, respectively. $(E),(F)$ Severe ERG changes; 21 and 25 months old, respectively. $(A)$, $(C)$ and $(E)$ represent sequential recordings from the same dog. Stimulus conditions and calibration are the same as in Fig. 4 . (From Nilsson et al. ${ }^{15}$ with permission.). 


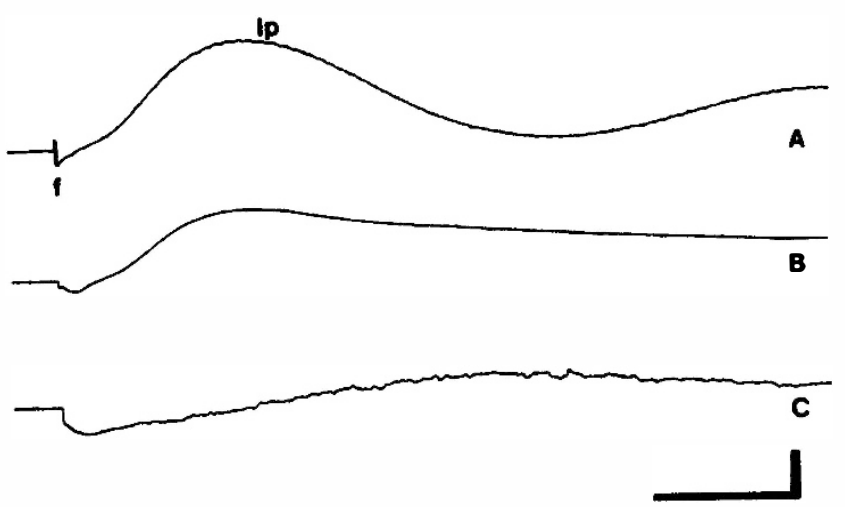

Fig. 7. Directly recorded standing potential of the eye with fast oscillation $(f)$ and light peak (lp) in English setters: (A) healthy control, 6 months old; (B) affected dog, 20 months old; $(C)$ affected dog, 24 months old. Time calibration: 5 minutes. Amplitude calibration: $1 \mathrm{mV}$. (From Nilsson et al. ${ }^{15}$ with permission.)

In dogs, which normally have comparatively small c-waves, the potential often becomes markedly negative as a result of an impairment of the positive

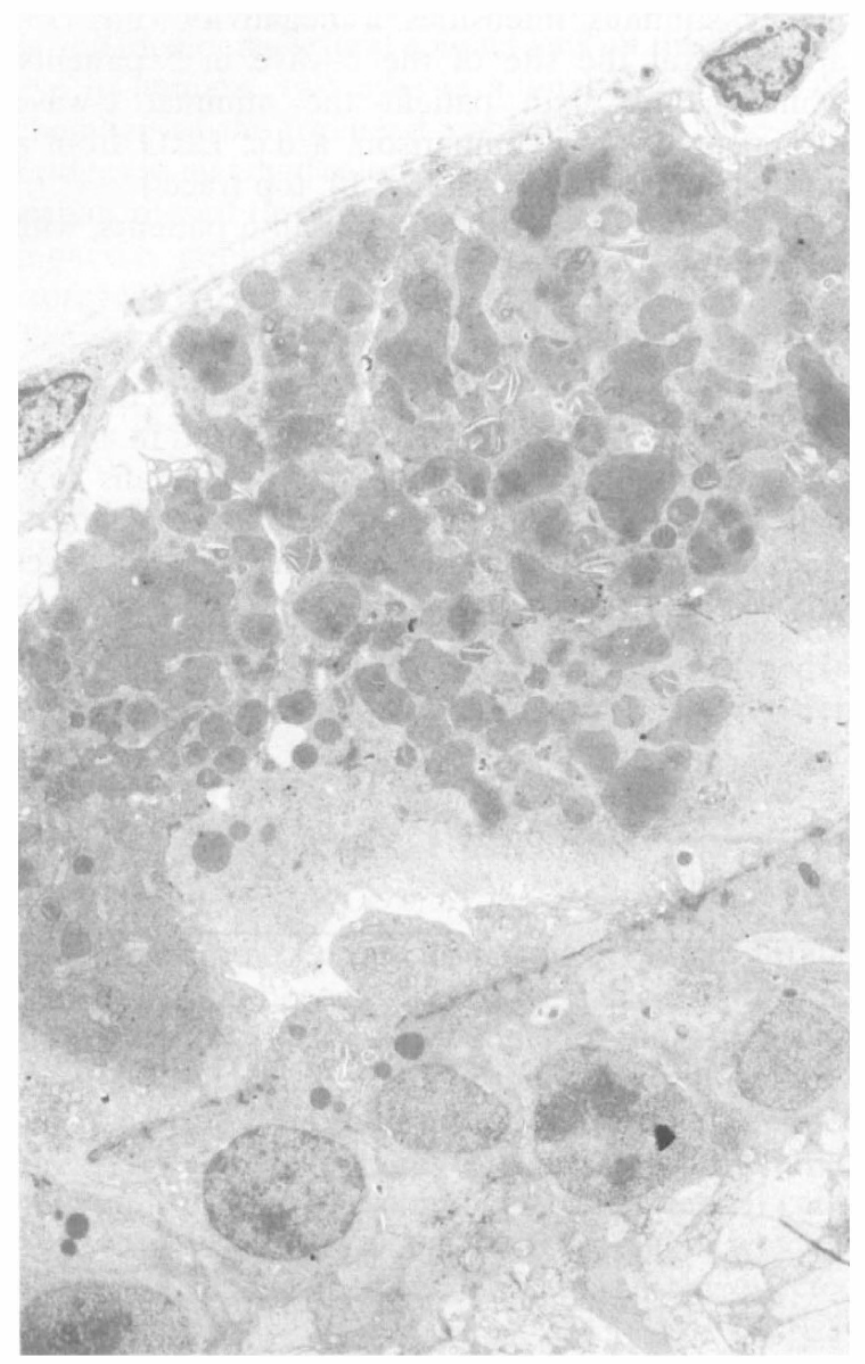

Fig. 8. Retinal pigment epithelial (RPE) cells and part of the retina (temporal central area) from a 2-year-old Polish Owczarek Nizinny dog affected by neuronal ceroid lipofuscinosis. The RPE cells are filled with inclusions. Photoreceptor inner segments are small and sparse. No outer segments are seen. $\times 2800$.
RPE component (PI) and an unchanged negative Müller cell component (slow PIII). In humans, the c-wave more often decreases to approach zero or to become slightly negative. In both animals and humans, the later stages of RPE disease also involve the retina with an overall reduced activity, i.e. a lowvoltage or an entirely flat ERG. It should be remembered, however, that the c-wave amplitude varies more in humans than in the experimental animals studied and that, in rare cases, humans with what appear to be normal eyes may lack a c-wave.
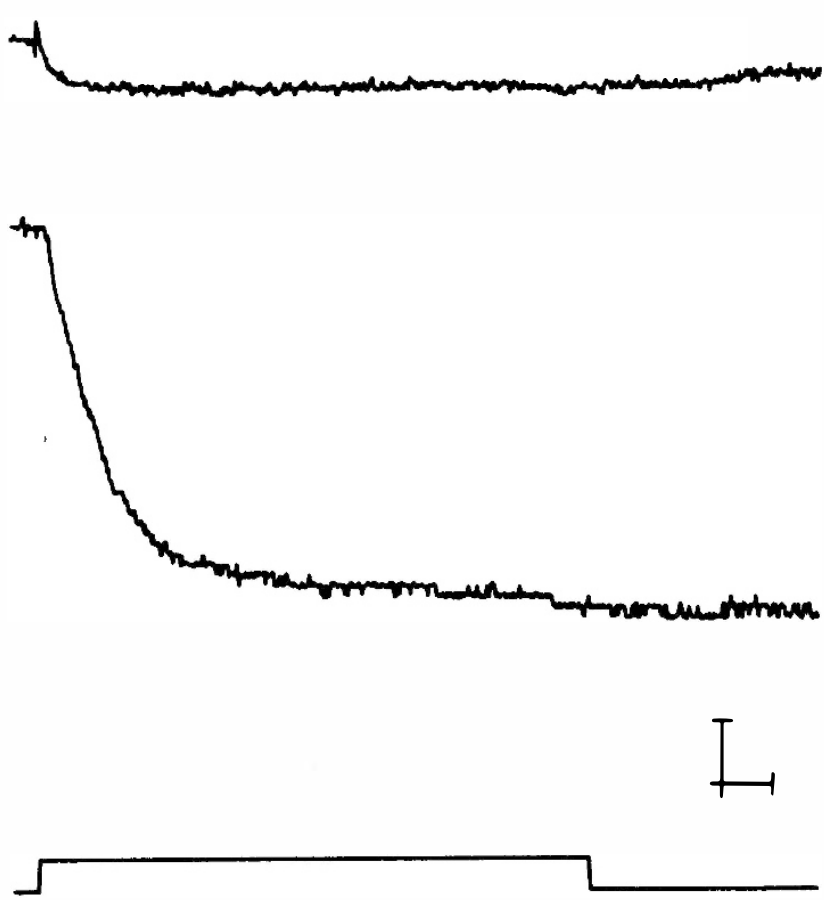

Fig. 9. The d.c. ERG recordings of slow potentials from a 2-year-old Polish Owczarek Nizinny dog affected by neuronal ceroid lipofuscinosis. Small $a$ - and $b$-waves and a low-amplitude negative potential at the site of the c-wave are found in a control dog (upper trace). No certain a- and $b$-waves, but a very large negative potential are found in an affected dog (lower trace). Stimulus intensity: about 75000 lux at the corneal level. Amplitude calibration: $300 \mu \mathrm{V}$. Time calibration 1.5 seconds. 


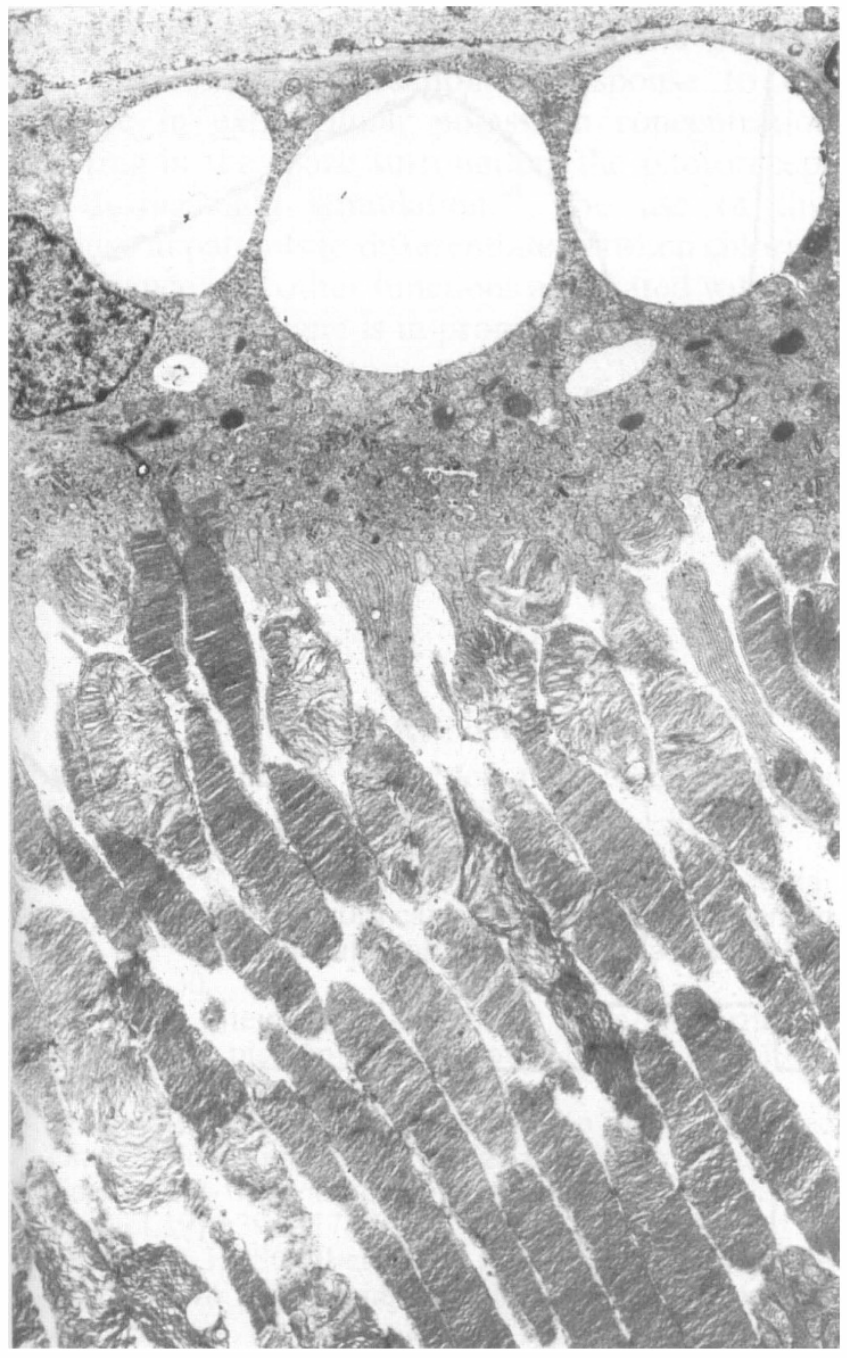

Fig. $10 R P E$ cell and photoreceptor outer segments (central-tapetal area) from a 7-month-old Briard dog with hereditary retinal dystrophy. Large electron-lucent inclusions are seen in the RPE. Several photoreceptor (presumably rod) outer segments are disorganised. $\times 4400$.

The significance of c-wave recordings is therefore greater in animal studies than in clinical examinations of humans.

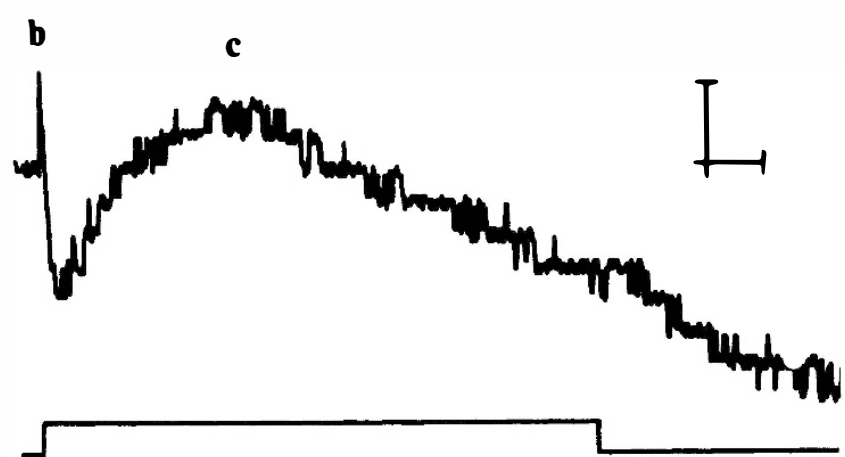

Fig. 11. The b-and c-waves of the d.c. ERG in a 2-yearold dark-adapted normal Briard dog. Stimulus intensity: 3.0 $\log$ units above the normal b-wave threshold (about 750 lux at the level of the cornea). Amplitude and time calibrations: $100 \mu \mathrm{V}$ and 1 second, respectively. (From Wrigstad et al. ${ }^{29}$ with permission.)
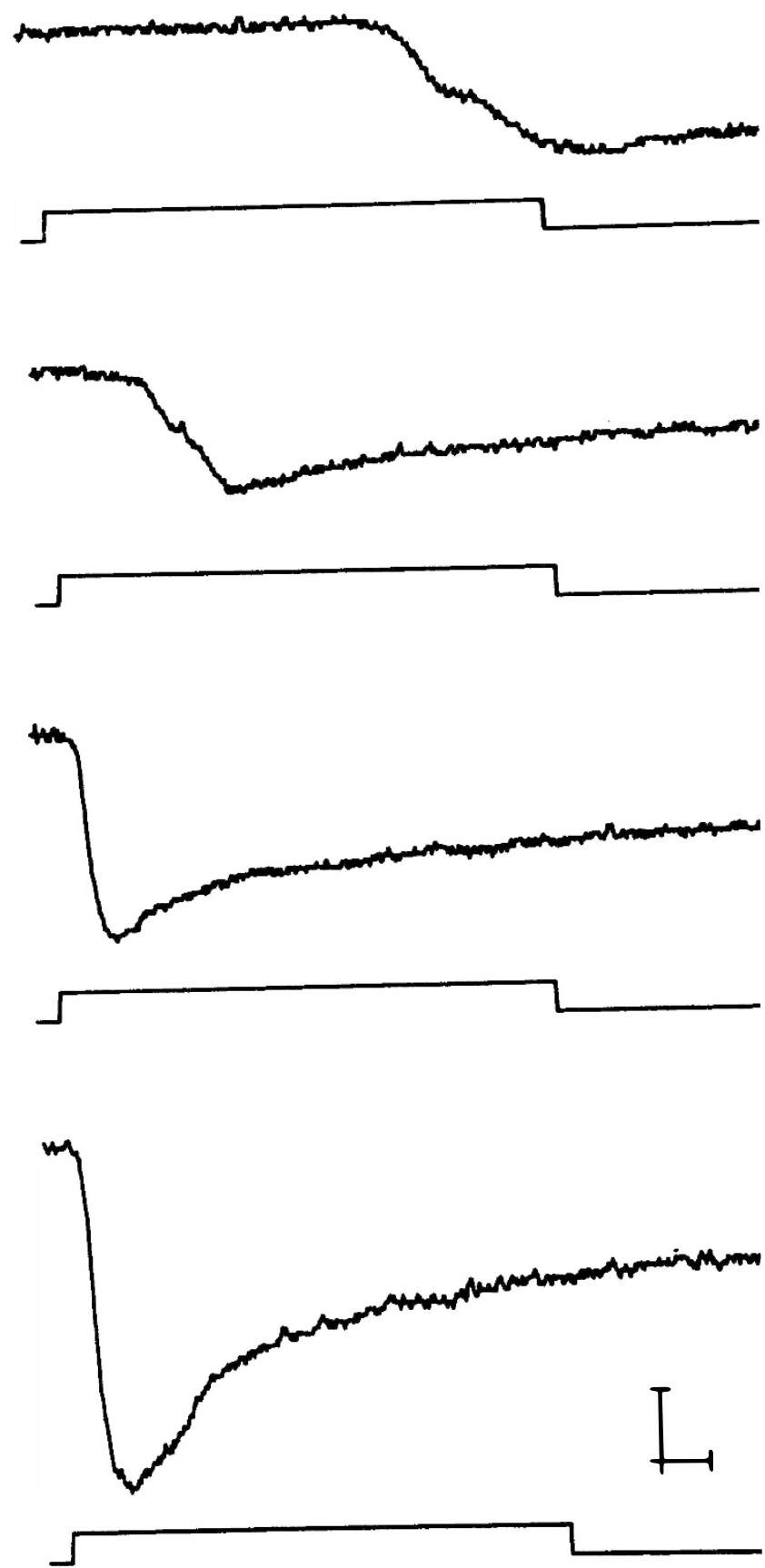

Fig. 12. A negative potential, growing substantially in amplitude (up to $2400 \mu \mathrm{V}$ ) with increasing stimulus intensity, and decreasing in latency (from approximately 6 to $<0.2$ second) and peak time (from about 11 to 1 second), is demonstrated in d.c. ERG recordings from a 7-month-old dark-adapted affected Briard dog. Stimulus intensities: 3.0 $(A), 3.5(B), 4.5(C)$ and 5.0 (D) log units, respectively, above the normal b-wave threshold (from 750 to 75000 lux, approximately, at the level of the cornea). Amplitude and time calibrations: $500 \mu \mathrm{V}$ and 1 second, respectively. (From Wingstad et al. ${ }^{29}$ with permission.)

Ceroid lipofuscinosis in English setters and in PON dogs is akin to Batten's disease in humans, involving cerebrocerebellar atrophy, progressive visual impairment, muscle weakness and dementia. Fingerprintlike inclusions are found in both cases. The ERG a- 


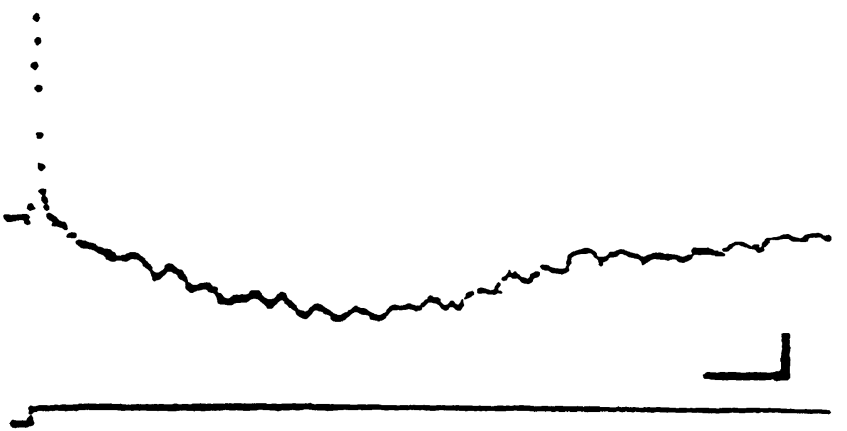

Fig. 13. The d.c. ERG from a patient with Best's disease (vitelliform macular degeneration). The $b$-wave is within normal limits. The c-wave is replaced by a slow negative potential. Stimulus intensity: 4.5 log units above the normal $b$-wave threshold. Stimulus duration: 20 seconds. Amplitude and time calibrations: $100 \mu \mathrm{V}$ and 2 seconds, respectively. (After Nilsson et al. ${ }^{30}$ with permission.)

and b-waves are absent or minimal. The d.c. ERG recordings were not performed in patients with Batten's disease.

The slow negative potential in Briard dogs seems to reflect the RPE changes, seen morphologically as inclusions. In addition, the latency of this response is extremely long. The delay may be caused by a serious error in the transduction cascade. Molecular genetic studies are in progress to elucidate this finding. It is not known whether the disease in Swedish Briard dogs is related to any of the inherited retinal or RPE diseases in humans. Certain clinical findings are rather similar to those in Leber's congenital amaurosis in humans, however: nystagmus, severely impaired vision from birth, normal fundi or subtle retinal spot-like changes and lack of ERG a- and b-waves. In addition, photoreceptor degeneration and, later, also inner retinal degeneration are seen in both diseases. Further investigation is needed to elucidate the question of a possible relationship.

Patients with congenital stationary night blindness (CSNB) of the Schubert-Bornschein type show a deep a-wave and no or a minimal b-wave, i.e. a socalled negative ERG. ${ }^{32}$ CSNB is regarded as a neuronal transmission defect, affecting the connection between the photoreceptors and the inner retina. ${ }^{33,34}$ It was found later that in addition to the a- and b-wave abnormalities, these patients show a deep negative potential at the site of the c-wave. ${ }^{35-37}$ The d.c. ERG of one of our patients is shown in Fig. 14 (lower traces). Such a prominent negativity seems to suggest an impairment of RPE function rather than an enhancement of the Müller cell potential. The EOG light peak was normal in all our patients. This does not exclude an RPE impairment, however, since the light peak reflects the pathway associated with basal chloride conductance and not all RPE functions. No RPE changes can be seen ophthalmoscopically in CSNB, however, and the microelec-
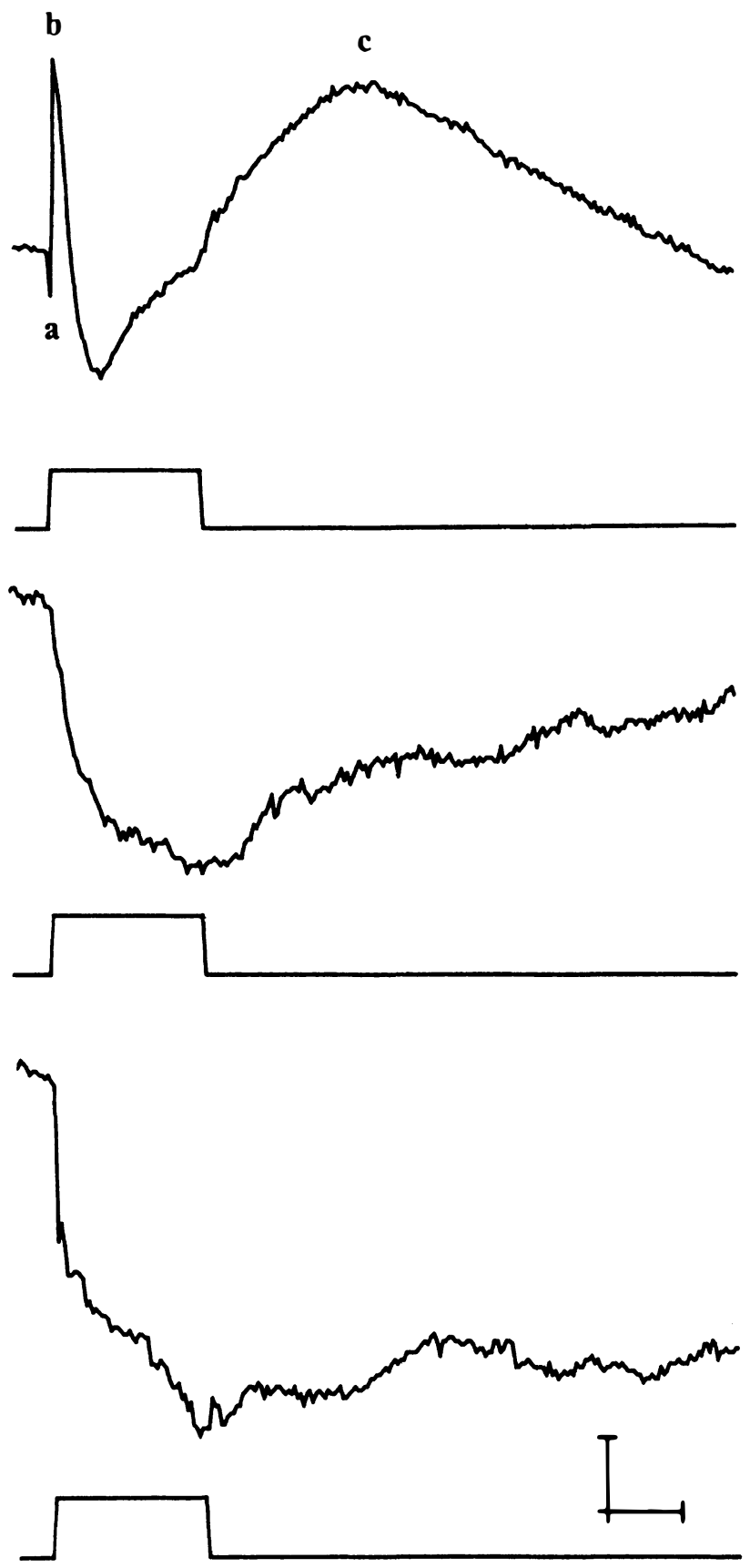

Fig. 14. Top trace: normal d.c. ERG in a human control with $a$-, $b$-and c-waves in response to a stimulus intensity of $13 \mathrm{~cd} / \mathrm{m}^{2}$. Middle and lower traces: d.c. ERG in two patients with the complete type of congenital stationary night blindness in response to stimulus intensities of 13 and 90 $\mathrm{cd} / \mathrm{m}^{2}$, respectively. The a-wave is prominent, and a trace of a b-wave may be seen. The response is characterised mainly by a slow negative potential, which becomes slightly less negative after the end of the stimulus. A small off-effect is seen in the lower trace. Amplitude and time calibrations: 100 $\mu V$ and 0.5 second, respectively. (From Takahashi et al. ${ }^{36}$ with permission.)

trode work which would be needed to solve the question of the origin of the slow negative potential cannot of course be performed in humans.

The fast oscillation, a negative potential with a maximum in humans at about $45-60$ seconds after 
the start of light stimulation, represents a delayed basal RPE hyperpolarisation in response to the decrease in extracellular potassium concentration occurring in the space surrounding the photoreceptors during light stimulation. ${ }^{38}$ The use of this response in patients to differentiate between chloride conductance and other functions associated with the basal RPE membrane is in progress.

These studies were supported by grants from the Swedish Medical Research Council (12X-734).

Key words: Retinal pigment epithelial disease, Retina, d.c. electroretinogram, Slow potentials, c-wave, Light peak.

\section{REFERENCES}

1. Faber DS. Analysis of the slow transretinal potentials in response to light [PhD thesis]. State University of New York at Buffalo, 1969.

2. Steinberg RH, Schmith R, Brown KT. Intracellular responses to light from cat pigment epithelium: origin of the electroretinogram c-wave. Nature 1970; 227:728-30.

3. Miller SS, Steinberg RH. Passive ionic properties of frog retinal pigment epithelium. J Membr Biol 1977; 36:337-72.

4. Oakley B II, Green DG. Correlation of light-induced changes in retinal extracellular potassium concentration with c-wave of the electroretinogram. J Neurophysiol 1976;39:1117-33.

5. Oakley B II, Steinberg RH, Miller SS, Nilsson SEG. The in vitro frog pigment epithelial hyperpolarisation in response to light. Invest Ophthalmol Vis Sci 1977;16:771-4.

6. Witkovsky P, Dudek FE, Ripps H. Slow PIII component of the carp electroretinogram. J Gen Physiol 1975;65:119-34.

7. Karwoski CJ, Proenza LM. Relationship between Müller cell responses, a local transretinal potential, and potassium flux. J Neurophysiol 1977;40:244-59.

8. Karwoski CJ, Proenza LM. Spatio-temporal variables in the relationship of neuronal activity to potassium and glial responses. Vision Res 1981;21:1713-8.

9. Noell WK. Studies on the electrophysiology and the metabolism of the retina. Project report US Air Force SAM Project no. 21-1201-0004. Randolph Field, Texas, 1953.

10. Suyama T. Electron microscopic study on experimental retinal degeneration induced by sodium iodate injection. Acta Soc Ophthalmol Jpn 1965;69:440-60.

11. Nilsson SEG, Knave B, Persson HE. Changes in ultrastructure and function of the sheep pigment epithelium and retina induced by sodium iodate. II. Early effects. Acta Ophthalmol (Copenh) 1977; 55:1007-26.

12. Nilsson SEG, Knave B, Persson HE. Changes in ultrastructure and function of the sheep pigment epithelium and retina induced by sodium iodate. III. Delayed effects. Acta Ophthalmol (Copenh) 1977; 55:1027-43.

13. Welinder E, Textorius O, Nilsson SEG. Effects of intravitreally injected DL- $\alpha$-aminoadipic acid on the cwave of the d.c.-recorded electroretinogram in albino rabbits. Invest Ophthalmol Vis Sci 1982;23:240-5.
14. Nilsson SEG. Other protocols for recording of electroretinograms and slower potential changes. In: Heckenlively JR, Arden GB, editors. Principles and practice of clinical electrophysiology of vision. Mosby Year Book: St Louis, 1991:328-33.

15. Nilsson SEG, Armstrong D, Koppang N, Persson P, Milde K. Studies on the retina and the pigment epithelium in hereditary canine ceroid lipofuscinosis. IV. Changes in the electroretinogram and the standing potential of the eye. Invest Ophthalmol Vis Sci 1983; 24:77-84

16. Griff ER, Steinberg RH. Origin of the light peak: in vitro study of Gecko gecko. J Physiol (Lond) 1982; 331:637-52.

17. Joseph D, Miller S. Alpha-adrenergic receptor activation at bovine RPE apical membrane affects basolateral membrane CI channels. Invest Ophthalmol Vis Sci 1989;30(3, Suppl):413.

18. Joseph D, Miller SS. Alpha-1-adrenergic modulation of $\mathrm{K}$ and $\mathrm{Cl}$ transport in bovine retinal pigment epithelium. J Gen Physiol 1992;99:263-90.

19. Gallemore RP, Steinberg RH. Effects of DIDS on the chick retinal pigment epithelium. II. Mechanism of the light peak and other responses originating at the basal membrane. J Neurosci 1989;9:1977-84.

20. Fujii S, Gallemore RP, Hughes BA, Steinberg RH. Direct evidence for a basolateral membrane $\mathrm{Cl}^{-}$ conductance in toad retinal pigment epithelium. Am J Physiol 1992;262:C374-83.

21. Arden GB, Kelsey JH. Changes produced by light in the standing potential of the human eye. J Physiol (Lond) 1962;161:190-204.

22. Nilsson SEG, Skoog K-O. Covariation of the simultaneously recorded c-wave and standing potential of the human eye. Acta Ophthalmol (Copenh) 1975;53: 721-30.

23. Nilsson SEG, Andersson BE. Corneal DC recordings of slow ocular potential changes such as the ERG c-wave and the light peak in clinical work: equipment and examples of results. Doc Ophthalmol 1988; 68:313-25.

24. Textorius O, Skoog K-O, Nilsson SEG. Studies on acute and late stages of experimental central retinal artery occlusion in the cynomolgus monkey. II. Influence on the cyclic changes in the amplitude of the c-wave of the ERG and in the standing potential of the eye. Acta Ophthalmol (Copenh) 1978;56:665-76.

25. Neville H, Armstrong D, Wilson B, Koppang N, Wehling C. Studies on the retina and the pigment epithelium in hereditary canine ceroid lipofuscinosis. III. Morphologic abnormalities in retinal neurons and retinal pigmented epithelial cells. Invest Ophthalmol Vis Sci 1980;19:75-86.

26. Goebel HH, Koppang N, Zeman W. Ultrastructure of the retina in canine neuronal ceroid lipofuscinosis. Ophthalmic Res 1979;11:65-72.

27. Wrigstad A, Nilsson SEG, Dubielzig R, Narfström K. Neuronal ceroid lipofuscinosis in the Polish Owczarec Nizinny (PON) dog: a retinal study. Doc Ophthalmol 1995;91:33-47.

28. Wrigstad A, Nilsson SEG, Narfström K. Ultrastructural changes of the retina and the retinal pigment epithelium in Briard dogs with hereditary congenital night blindness and partial day blindness. Exp Eye Res 1992;55:805-18.

29. Wrigstad A, Narfström K, Nilsson SEG. Slowly progressive shanges of the retina and the retinal pigment epithelium in Briard dogs with hereditary retinal dystrophy. Doc Ophthalmol 1994;87:337-54. 
30. Nilsson SEG, Wrigstad A, Narfström K. Changes in the DC electroretinogram in Briard dogs with hereditary congenital night blindness and partial day blindness. Exp Eye Res 1992;54:291-6.

31. Nilsson SEG, Skoog K-O. The ERG c-wave in vitelliruptive macular degeneration (VMD). Acta Ophthalmol (Copenh) 1980;58:659-66.

32. Schubert G, Bornschein H. Beitrag. zur Analyse des menschlichen Elektroretinogramms. Ophthalmologica 1952;123:396-413.

33. Carr RE, Ripps H, Siegel IM, Weale RA. Rhodopsin and the electrical activity of the retina in congenital night blindness. Invest Ophthalmol Vis Sci 1966; 5:497-507.

34. Ripps H. Night blindness revisited: from man to molecules. Proctor lecture. Invest Ophthalmol Vis Sci 1982;23:588-609.
35. Heilig P, Thaler A, Bornschein H. Slow potentials of ERG in hemeralopia congenita. In: Xth ISCERG Symposium, Los Angeles. Doc Ophthalmol Proc Ser 1972;219-24.

36. Takahashi Y, Onoe S, Asamizu N, Mori T, Yoshimura Y, Tazawa Y. Incomplete congenital stationary night blindness: electroretinogram c-wave and electrooculogram light rise. Doc Ophthalmol 1988;70:67-75.

37. Wrigstad A, Nilsson SEG. A slow negative potential in the d.c. electroretinogram of patients with congenital stationary night blindness. Clin Vision Sci 1993; 8:171-6.

38. Griff ER, Steinberg RH. Changes in apical $\left[\mathrm{K}^{+}\right]$ produce delayed basal membrane responses of the retinal pigment epithelium in the gecko. J Gen Physiol 1984;83:193-211. 